\title{
An Isolated Soft-Switching Bidirectional Buck-Boost Inverter for Fuel Cell Applications
}

\author{
Lianghua Zhang ${ }^{\dagger}, \mathrm{Xu}$ Yang*, Wenjie Chen*, and Xiaofeng Yao* \\ †* School of Electrical Engineering, Xi'an Jiaotong University, Shaanxi, China
}

\begin{abstract}
This paper presents a new isolated soft-switching bidirectional buck-boost inverter for fuel cell applications. The buckboost inverter combines an isolated DC-DC converter with a conventional inverter to implement buck-boost DC-DC and DC-AC conversion. The main switches achieve zero voltage switching and zero current switching by using a novel synchronous switching SVPWM and the volume of the transformer in the forward and fly-back mode is also minimized. This inverter is suitable for wide input voltage applications due to its high efficiency under all conditions. An active clamping circuit reduces the switch's spike voltage and regenerates the energy stored in the leakage inductance of the transformer; therefore, the overall efficiency is improved. This paper presents the operating principle, a theoretical analysis and design guidelines. Simulation and experimental results have validated the characteristics of the buck-boost inverter.
\end{abstract}

Key Words: Active voltage clamping, Buck-boost inverter, Fuel cell power-conditioning system, Synchronous switching SVPWM

\section{INTRODUCTION}

With the increase in demand for clean energy applications, fuel cells, as one of the more promising sources, draw more and more attention in the power electronics community. The reason for this attention is that fuel cells convert chemical energy into electrical energy with no pollution, high efficiency and low noise [1]. Unfortunately, some inherent drawbacks exist in fuel cell applications [1]-[3]. These include an output voltage that varies widely with age and output current, and a low-frequency current ripple that reduce conversion efficiency. In addition, fuel cells spend take some minutes to cold start and they respond slowly to step loads. In order to maximize fuel cell efficiency, the operating point of a fuel-cell stack should approach the maximum power-delivery point. For regenerative fuel-cell applications, bidirectional power capability is necessary to generate hydrogen and oxygen. Thus, fuel cell Power-Conditioning Systems (PCS) should exhibit the following characteristics [1]-[3].

- PCSs should boost and regulate the low DC voltage from a fuel cell to a high DC voltage with a small current ripple and they should convert $\mathrm{DC}$ to $\mathrm{AC}$ for electric utility interfaces, automotive applications, and stationary loads.

- PCSs should allow for wide voltage regulation and be suitable for high-power systems.

- To satisfy domestic and international safety standards for electronic equipment, an isolated transformer is required

Manuscript received Dec. 9, 2009; revised Apr. 3, 2010

† Corresponding Author: lilienthal_zhang@163.com

Tel: +086-29-82665223, Fax: +086-29-82665223, Xi'an Jiaotong Univ.

* School of Electrical engineering, Xi' an Jiaotong University, China for a higher voltage or higher power PCS.

- Secondary energy sources and energy storage are necessary for fast response during transients and start-up.

- PCSs should operate efficiently under all conditions and add little to the system cost.

Because conventional inverters cannot satisfy all of these requirements, it is urgent that a new circuit topology for fuel cell PCSs be devloped. The presented circuit topologies from the power electronics scientific community are divided into two groups, which are: 1) multi-stage topologies [3]-[15] and 2) single stage topologies [16]-[23].

The multi-stage topologies usually consist of a front dcdc converter and a dc-ac inverter. The front dc-dc converter for a PCS boosts the wide-drop voltage of a fuel cell to a higher level for the dc-ac inverter. The proposed front-end dc-dc converters are classified as boost converters [3]- [5], push-pull converters [6], [7], half bridge converters [8], fullbridge converters [9]-[16], wide input and high step-up dcdc converters [17], [18] or a LLC resonant converter [19]. In addition, conventional hard switching inverters [11], [12], [14], soft-switching inverters [6], [15] and high frequency link inverters [3], [4] have been presented as dc-ac inverters for PCSs. However, in the multi-stage topologies, it is not easy to achieve low cost and high efficiency due to the large number of power switches and the multiple electric energy processing.

In single stage topologies, voltage source [20], [21] and current source [22], [23] buck-boost inverters have been researched as fuel cell PCSs. However, these converters have the limitations of a small voltage gain and no isolation. A Z-source inverter [24] has been presented for fuel cell applications, but three-phase inverters operate with hard switching and do not 


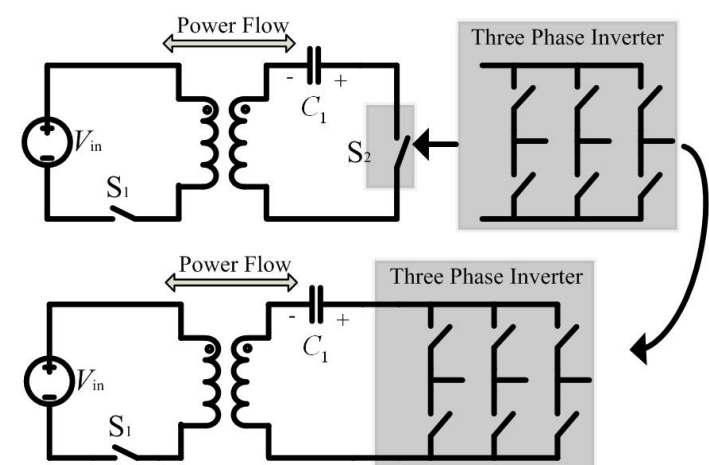

(a) Derivation of the topology

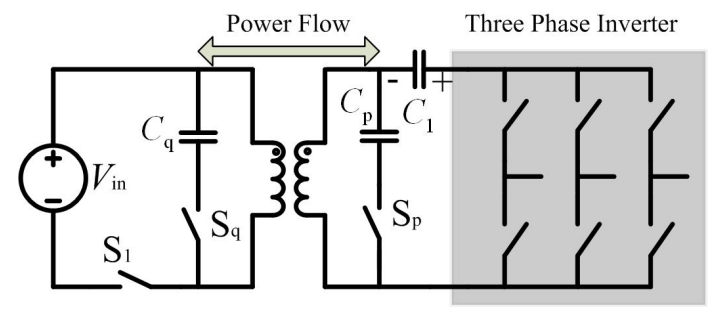

(b) Buck-Boost Inverter with active clamping circuit

Fig. 1. Buck-Boost Inverter.

implement electrical isolation. Although many papers [25], [26] have introduced high-frequency link inverters to minimize the transformer volume or the dc link capacitors, complexity and component cost detract from these topologies.

This paper presents a novel isolated soft-switching bidirectional buck-boost inverter for fuel cell applications. A conventional inverter displaces one or more of the switches of an isolated DC-DC converter to boost the input voltage to a higher level and to invert it to AC voltage with soft switching. By means of a novel synchronous switching SVPWM, the magnetizing inductance current freewheels through the antiparallel diode of the main switches. Therefore, the switches of a conventional inverter achieve Zero Voltage Switching (ZVS) and Zero Current Switching (ZCS). The active clamping circuit reduces the spike voltage of the switches and recovers the leakage inductance energy. The experimental results from a $1.5 \mathrm{~kW}$ prototype confirm the theoretical analysis. The proposed inverter is a good alternative to wide input voltage applications.

\section{THE Buck-Boost InVERTER}

Fig.1 shows an isolated bidirectional buck-boost inverter (BBI). The proposed topology is derived by using a conventional three-phase voltage source inverter to replace one switch of a bidirectional fly-back converter. In this topology, the voltage source inverter works as a turned-off switch in the inverting state, and it works as a turned-on switch in the shooting-through state. A conventional half-bridge inverter, a full-bridge inverter or some other multi-phase inverter operates as voltage source inverters. The transformer of a BBI is very different from that of a fly-back converter because it operates in both the forward and fly-back mode. To reduce the switch's spike voltage caused by the leakage inductance of the transformer, fig.1 (b) illustrates the active clamping circuits,

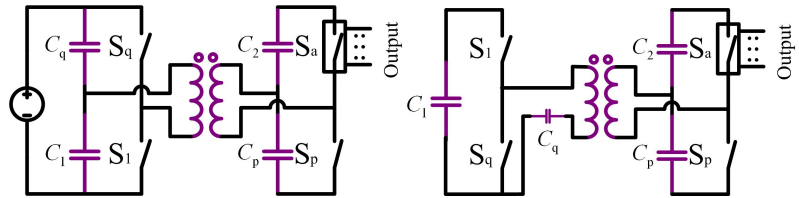

(a) Asymmetrical half bridge

(b) half bridge resonant inverter

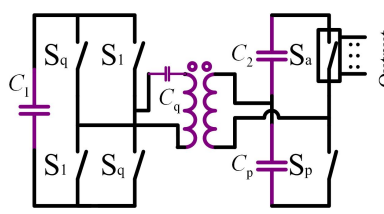

(c) full bridge resonant inverter (d) conventional inverter

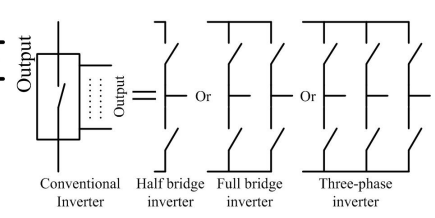

Fig. 2. The derivate topological family.

( 1 : : Switching devices - IGBT, MOSFET, DIODE, IGCT etc or the combination of the switches.)

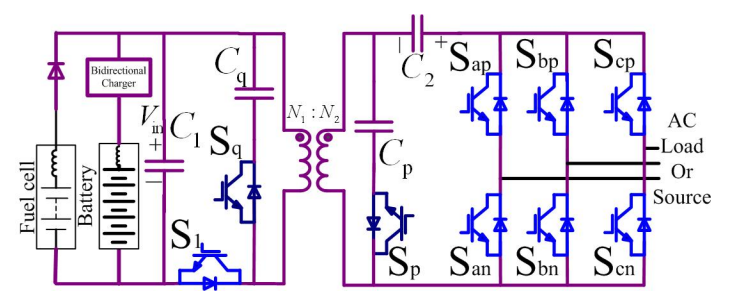

Fig. 3. The proposed three-phase buck-boost inverter for fuel cell PCS.

where $S_{p}$ and the capacitor $C_{3}$ clamp the switch's voltage in a three-phase inverter, and $S_{q}$ and the capacitor $C_{4}$ clamp the voltage of $S_{1}$.

Based on this concept, we derived the topological family of a buck-boost inverter using another isolated DC-DC converter. The isolated DC/DC converter employs a half bridge topology or a full bridge topology with a high frequency transformer, as shown in Fig. 2. The voltage source inverters illustrated in Fig.2 (d) replace one or more of the switches of the isolated DC/DC converter. Fig. 2 (a) shows a derivative topology using an asymmetrical half bridge converter, where the input voltage changes within a narrow range. When a resonant converter based on a half bridge or a full bridge is combined with a conventional voltage source inverter, the other topologies are derived as shown in Fig.2 (b)-(c). Besides the above configurations, any other capacitor can connect with the DC voltage source supplied from a battery, fuel cell or rectifier, while the inverter's output connects with a utility grid, a generator or some other load.

This paper presents a three-phase buck-boost inverter (BBI) for a fuel cell PCS to analyze the operation of the topological family of buck-boost inverters. A detailed configuration of the derived topology is shown in Fig. 3. The parallel battery acts as a secondary energy source for fast responses during transients and start-up. The bidirectional charger is used to charge or discharge the battery efficiently. When the AC load operates in regeneration, the battery is charged through the bidirectional BBI. When the fuel cell's output voltage drops with the load current, the duty cycle of $S_{1}$ is controlled to regulate the dc link voltage of the three-phase inverter and maintain the AC output. 


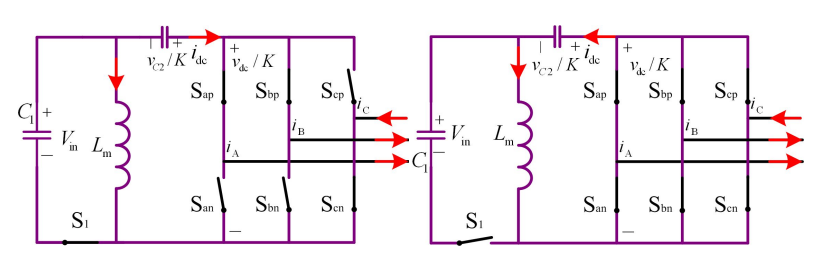

(a) Inverting state

(b) Shooting-through zero state

Fig. 4. Two kinds of switching state in buck-boost mode.

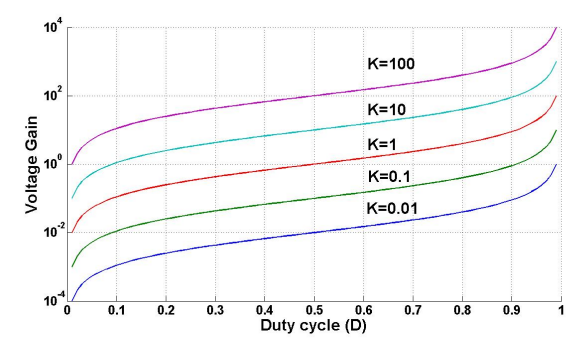

Fig. 5. Voltage gain as a function of duty cycle D.

\section{Operating Principles And Circuit Analysis}

To simplify the circuit analysis, the equivalent circuit of a BBI operating in buck-boost mode neglects the active clamping circuit, as shown in Fig. 4. The electrical parameters are transferred to the primary side, where the turn's ratio $K$ is equal to $N_{2} / N_{1}$ and the inductance $L_{m}$ is the transformer's magnetizing inductance. In this analysis, it is assumed that the BBI operates at the steady state in one switching cycle. In addition, this analysis neglects the slight impact from the leakage inductance of the transformer.

Based on these assumptions, the circuit operation in one switching cycle can be divided into two kinds of switching states. One is the inverting state and the other is the shootingthrough zero state. $D$ is defined as the switching-on duty cycle of $S_{1}, v_{L m}$ is the magnetizing inductance voltage, $v_{C 1}$ and $v_{C 2}$ are the capacitors' voltages. In a three-phase inverter, $v_{d c}$ is the dc link voltage and $i_{d c}$ is the dc link current. The arrowheads indicate the current direction.

\section{A. Inverting state}

$S_{1}$ is turned ON while the inverter is OFF $\left(S_{1}=1, S_{x p}\right.$ \& $S_{x n}=0$, e.g. $S_{a b c p}=110, S_{a b c n}=001$ ), as shown in Fig. 4 (a). The voltage sources $v_{c 1}$ and $v_{c 2}$ act as the dc link voltage together for the three-phase inverter. It is obvious that the transformer operates in both the forward and fly-back modes.

From the equivalent circuit, we can derive that:

$$
\begin{aligned}
& L_{m} \frac{d i_{L_{m}}}{d t}=v_{C_{1}} \\
& v_{d c}=K v_{C_{1}}+v_{C_{2}} .
\end{aligned}
$$

\section{B. Shooting-through zero state}

The inverter is turned ON while $S_{1}$ is OFF $\left(S_{1}=0\right.$, $S_{a b c p}=111, S_{a b c n}=111$ ), as shown in Fig. 4 (b). The current of the inductance charges the capacitor $C_{2}$.

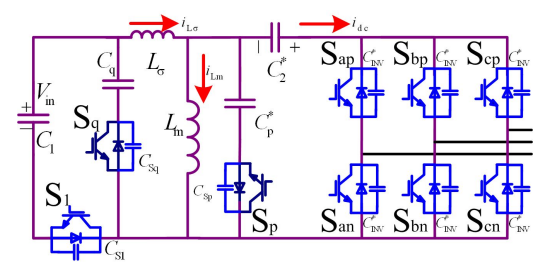

Fig. 6. The BBI's equivalent circuit.

According to the circuit principle, the formulas are derived as:

$$
\begin{aligned}
& L_{m} \frac{d i_{L_{m}}}{d t}=-\frac{v_{c_{2}}}{K} \\
& v_{d c}=0 .
\end{aligned}
$$

The magnetizing inductance average voltage during one switching period $\mathrm{T}$ should be zero at the steady state. From equations (1) and (3), the voltage gain $\mathrm{G}$ is described by (5). Fig. 5 shows the voltage gain curve under different turn's ratios, where $\mathrm{G}$ is continuously regulated by the duty cycle $D$.

$$
G=\frac{v_{C_{2}}}{v_{i n}}=\frac{v_{C_{2}}}{v_{C_{1}}}=\frac{K D}{1-D} .
$$

Similarly, the average dc link voltage during one switching period is described by (6), which is equal to the $C_{2}$ voltage.

$$
\bar{v}_{d c}=D\left(K v_{C_{1}}+v_{C_{2}}\right)=G v_{C_{1}}=v_{C_{2}} .
$$

The maximum switch voltage stress at the primary side and secondary side are expressed by (7) and (8) respectively.

$$
\begin{aligned}
& V^{\text {Primary }}=\frac{v_{i n}}{1-D} \\
& V^{\text {Secondary }}=\frac{K v_{i n}}{1-D} .
\end{aligned}
$$

\section{SofT-SWITCHING ANd ACTIVE VOLTAGE CLAMPING CIRCUIT ANALYSIS}

The detailed equivalent circuit of a BBI is shown in Fig. 6, where $L_{\sigma}$ is the total leakage inductance of the transformer and the capacitors $C_{S 1}, C_{S p}, C_{S q}$ and $C_{I N V}^{*}$ are the IGBT's output capacitors.

\section{A. DC-AC Mode}

In the DC-AC mode, the power is transferred from a fuel cell to the AC load. The main operating waveforms are shown in Fig. 7 and the operating stages during half a triangle carrier period are shown in Fig. 8.

First stage $\left(t_{0}-t_{1}\right): S_{1}$ is OFF and the three-phase inverter operates in the shooting-through zero state. The positive magnetizing current $i_{L m}$ freewheels through the inverter's antiparallel diodes. $v_{c p}$ and $v_{c q}$ are kept constant. Their values are $K V_{i n}+\Delta V_{C_{p 1}}$ and $V_{c 2} / K+\Delta V_{C_{q 1}}$ respectively.

Second stage $\left(t_{1}-t_{2}\right): S_{1}$ is still OFF and the threephase inverter is switched to the inverting state $\left(S_{a b c p}=110\right.$, $\left.S_{a b c n}=001\right)$. The IGBTs $S_{a n}, S_{b n}$ and $S_{c p}$ are turned off with ZCS because the magnetizing inductance current still freewheels through the anti-parallel diodes. 


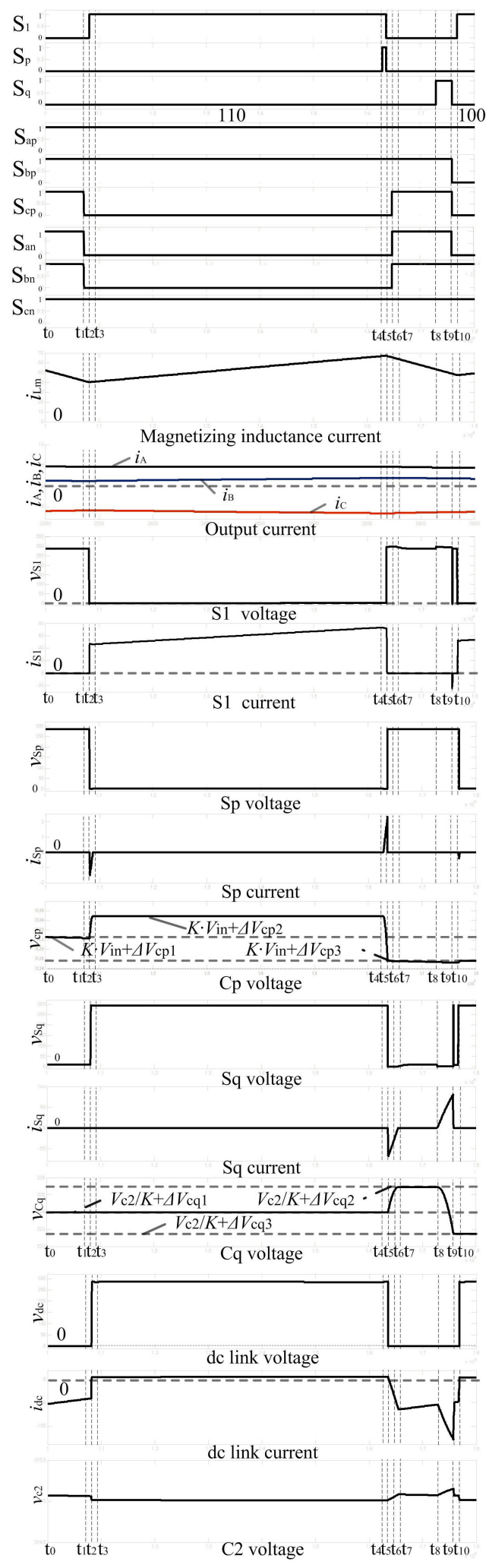

Fig. 7. DC-AC operating waveforms.

Third stage $\left(t_{2}-t_{3}\right): S_{1}$ is turned on at $t_{2}$ as shown in Fig. 8 (c). $C_{S 1}$ is fast discharged from $V_{i n}+V_{C_{2}} / K$ to zero and $C_{s q}$ is fast charged from $\Delta V_{C_{q 1}}$ to $V_{i n}+V_{C 2} / K+\Delta V_{C_{q 1}}$. Because $d i / d t$ is weakened by the leakage inductance $L_{\sigma}$, the leakage inductance current $i_{L_{\sigma}}$ begins to increase slowly.

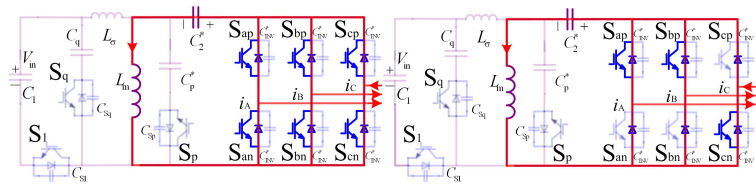
(a) $t_{0}-t_{1}$
(b) $t_{1}-t_{2}$

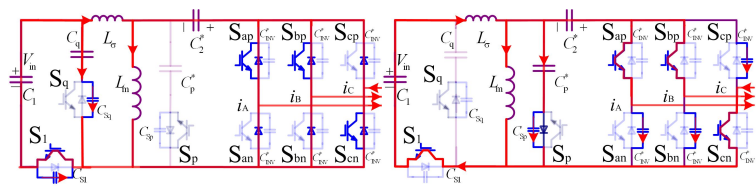

(c) $t_{2}$

(d) $t_{2}-t_{3}$

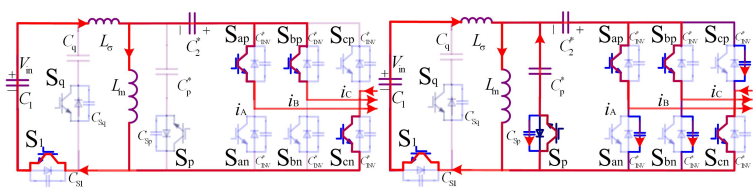

(e) $t_{3}-t_{4}$

(f) $t_{4}$

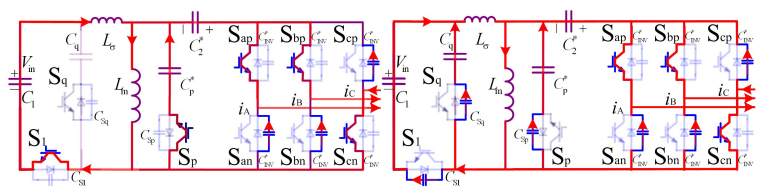

(g) $t_{4}-t_{5}$

(h) $t_{5}$

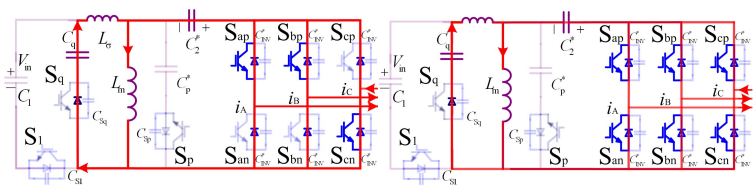

$\begin{array}{ll}\text { (i) } t_{5}-t_{6} & \text { (j) } t_{6}-t_{7}\end{array}$

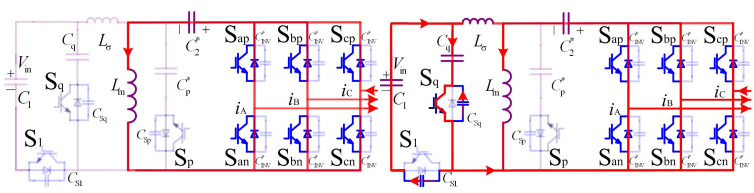

(k) $t_{7}-t_{8}$

(1) $t_{8}$

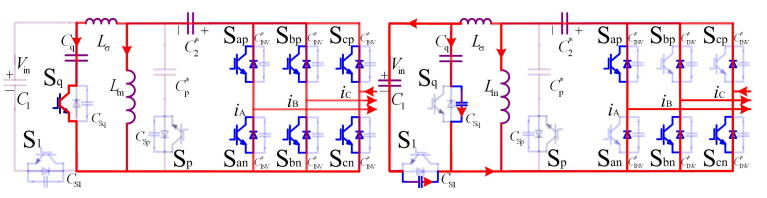

(m) $t_{8}-t_{9}$

(n) $t_{9}$

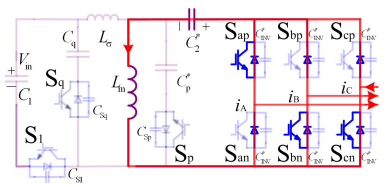

(o) $t_{9}-t_{10}$

Fig. 8. DC-AC operating stages.

When the current $i_{L_{\sigma}}$ is lower than $i_{L m}+K\left(i_{A}+i_{B}\right)$, the three-phase inverter still keeps the shooting-through zero state. Although the shooting-through zero state changes in this stage, it is only illustrated that the anti-parallel diodes of the threephase inverter are conducting. When the current $i_{L_{\sigma}}$ exceeds $i_{L m}+K\left(i_{A}+i_{B}\right)$ as shown in Fig. 8 (d), the output capacitors 
$S_{a n}, S_{b n}$ and $S_{c p}$ begin to be charged from zero to $K V_{i n}+$ $V_{c 2}+\Delta V_{C_{p 1}}$ and $C_{s p}$ is discharged to zero. Then, the capacitor $C_{p}$ continues to be charged to $K V_{i n}+\Delta V_{C_{p 2}}$ until the current $i_{s p}$ drops to zero. $C_{p}$ is so sufficient that the ripple voltage $\Delta V_{C_{p 2}}$ is very small when compared to $K V_{i n}$. The output capacitors $S_{a n}, S_{b n}$ and $S_{c p}$ are also charged to $K V_{i n}+V_{C 2}+$ $\Delta V_{C_{p 2}}$. After that, $C_{s p}$ is recharged to $\Delta V_{C_{p 2}}$ and the inverter dc link voltage drops to $K V_{i n}+V_{C 2}$. Therefore, the active voltage clamping circuit for the three-phase inverter reduces the dc link spike voltage.

Fourth stage $\left(t_{3}-t_{4}\right)$ : During this period, the current $i_{L m}$ increases continuously.

Fifth stage $\left(t_{4}-t_{5}\right): S_{p}$ is turned on at $t_{4}$ as shown in Fig. 8 (f). $C_{s p}$ is fast discharged from $\Delta V_{C_{p 2}}$ to zero and the output capacitors $S_{a n}, S_{b n}$ and $S_{c p}$ are also charged to $K V_{i n}+$ $V_{C 2}+\Delta V_{C_{p 2}}$. Then, $C_{p}$ is discharged from $K \cdot V_{i n}+\Delta V_{C_{p 2}}$ to $K \cdot V_{i n}+\Delta V_{C_{p 3}}$ and the output capacitors $S_{a n}, S_{b n}$ and $S_{c p}$ are also discharged to $K V_{i n}+V_{C 2}+\Delta V_{C_{p 3}}$. During this period, the leakage inductance current $i_{L_{\sigma}}$ decreases.

Sixth stage $\left(t_{5}-t_{6}\right)$ : This stage starts when $S_{1}$ and $S_{p}$ are turned off simultaneously, as shown in Fig. 8 (h). $C_{s 1}$ and $C_{s q}$ begin to be charged and discharged respectively. The rate of voltage change depends on $i_{L_{\sigma}}$ at $t_{5} . C_{s p}$ and the output capacitors $S_{a n}, S_{b n}$ and $S_{c p}$ also begin to be charged and discharged respectively. In addition, the rate of change is determined primarily by $i_{S p}$. After the charging/discharging, as shown in Fig. 8 (i), the current $i_{L_{\sigma}}$ is commutated to the anti-parallel diode of $S_{p}$ and the current $i_{L m}$ is commutated to the anti-parallel diodes of the three-phase inverter. Moreover, $C_{q}$ is charged from $V_{C 2} / K+\Delta V_{C_{q 1}}$.

Seventh stage $\left(t_{6}-t_{7}\right): S_{a n}, S_{b n}$ and $S_{c p}$ are simultaneously turned on at $t_{6}$. The zero voltage turn-on is achieved by the gating on these devices while the anti-parallel diodes are conducting. $C_{q}$ is charged to $V_{C 2} / K+\Delta V_{C_{q 2}}$ until $i_{L_{\sigma}}$ drops to zero and $C_{s 1}$ is also charged to $V_{i n}+V_{C 2} / K+\Delta V_{C_{q 2}}$. Finally, $C_{s q}$ is recharged to $\Delta V_{C_{q 2}}$, and $C_{S 1}$ is discharged to $V_{i n}+V_{C 2} / K$. According to the above analysis, the spike voltage of $S_{1}$ is restricted due to the active voltage clamping circuit.

Eighth stage $\left(t_{7}-t_{8}\right)$ : The three-phase inverter is still operating in the shooting-through zero state. The magnetizing current $i_{L m}$ keeps on decreasing at the rate of $V_{C 2} /\left(K^{2} L_{m}\right)$, and $C_{2}$ is charged with a small voltage ripple.

Ninth stage $\left(t_{8}-t_{9}\right): S_{q}$ is turned on at $t_{8}$, as shown in Fig. 8 (1). $C_{S q}$ is fast discharged from a low voltage $\Delta V_{C_{q 2}}$ to zero and $C_{s 1}$ is charged to $V_{i n}+V_{C 2} / K+\Delta V_{C_{q 2}}$. Then, $C_{q}$ begins to resonate with $L_{\sigma}$, and $C_{q}$ is discharged from $V_{C 2} / K+\Delta V_{C_{q 2}}$ to $V_{C 2} / K+\Delta V_{C_{q 3}}$.

Tenth stage $\left(t_{9}-t_{10}\right): S_{q}, S_{a n}, S_{b p}$ and $S_{c p}$ are turned off at $t_{9}$. The zero current turn-offs are achieved by gating off $S_{a n}$ and $S_{b p}$ while the anti-parallel diodes are conducting. After $t_{9}$, the current $i_{L_{\sigma}}$ is commutated to the anti-parallel diode of $S_{1}$, and it decreases quickly until it drops to zero. Finally, $C_{s q}$ is recharged to $\Delta V_{C_{q 3} 3}$, and $C_{S 1}$ is discharged to $V_{i n}+V_{C 2} / K$.

\section{B. AC-DC Mode}

When the battery is charged, the power flows from the AC port to the DC side. Fig. 9 shows the main operating
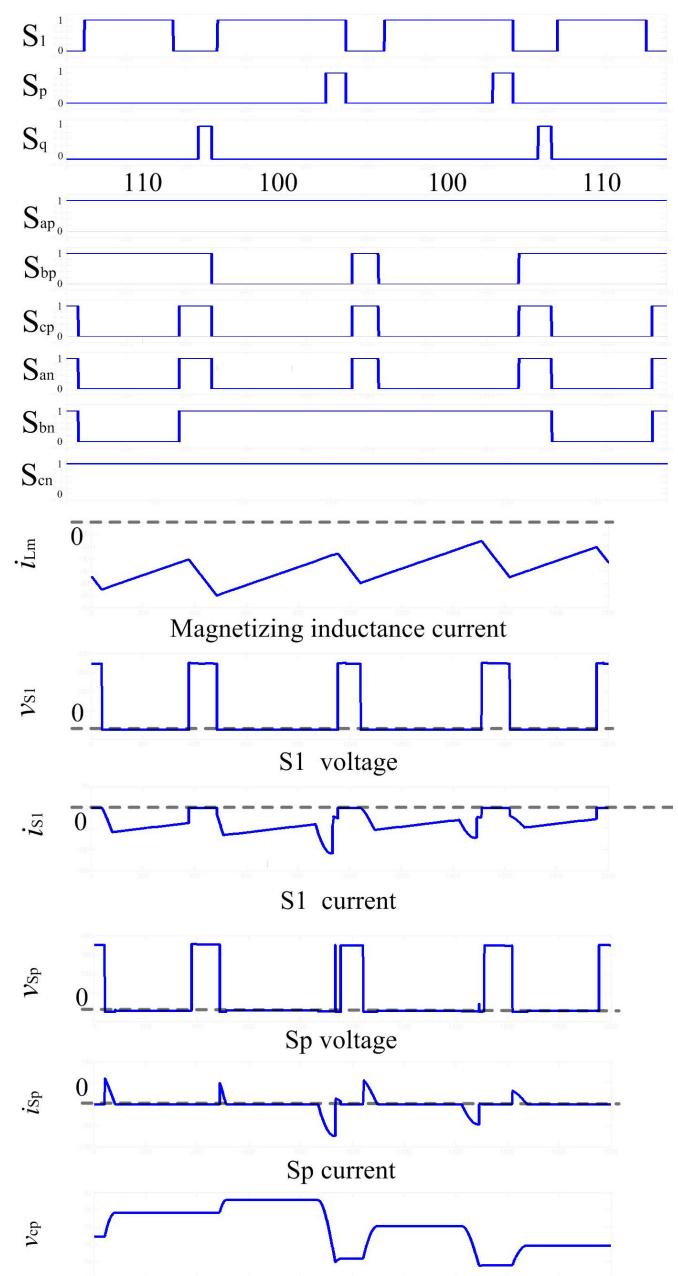

Cp voltage
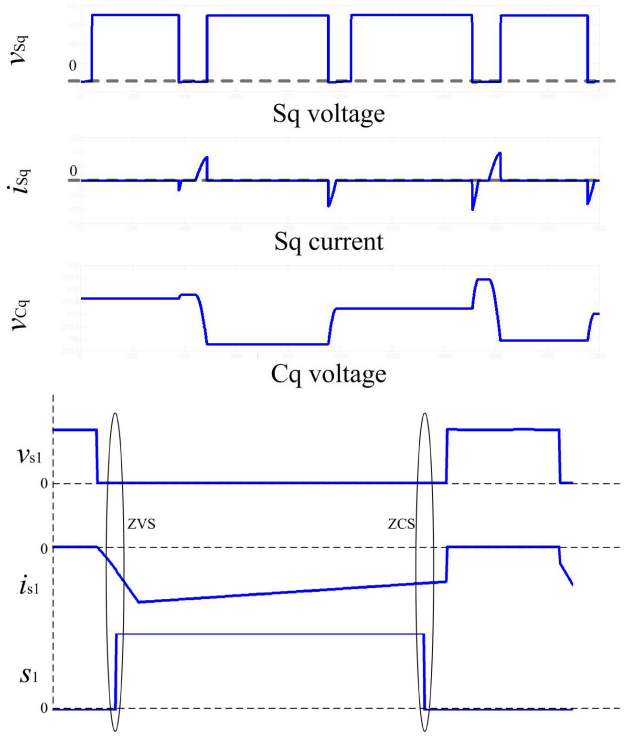

Fig. 9. AC-DC operating waveforms.

waveforms during one triangle carrier period. In this mode, the switches $S_{p}$ and $S_{q}$ still keep ZVS operation, but the magnetizing inductance current is reversed. Because the antiparallel diode of $S_{1}$ is always conducting during the $S_{1}$ switching process, $S_{1}$ achieves ZCS and ZVS. A description 


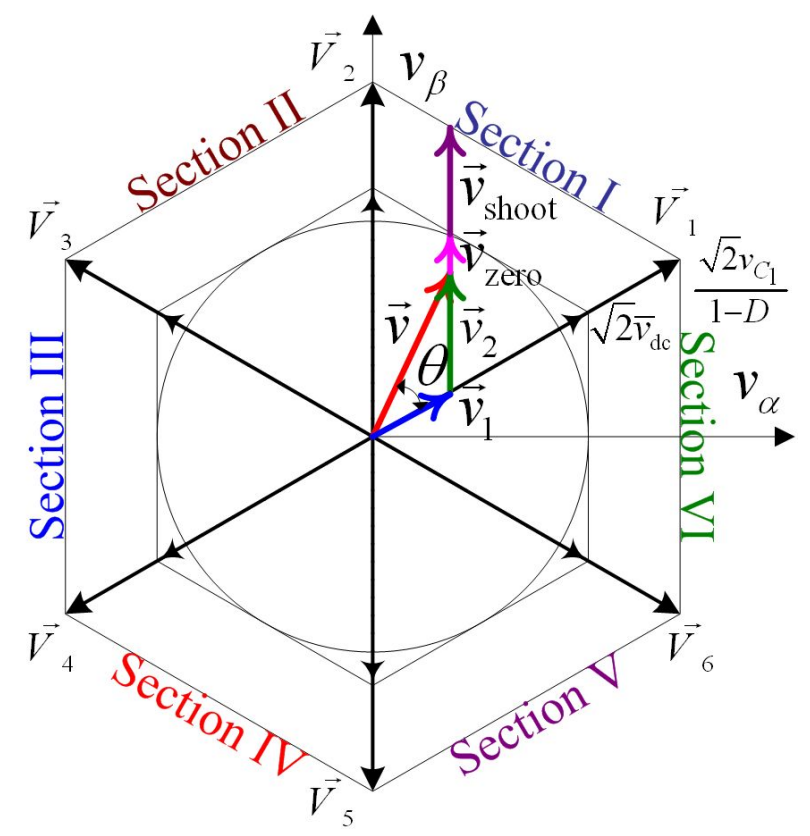

Fig. 10. Vectorial combination.

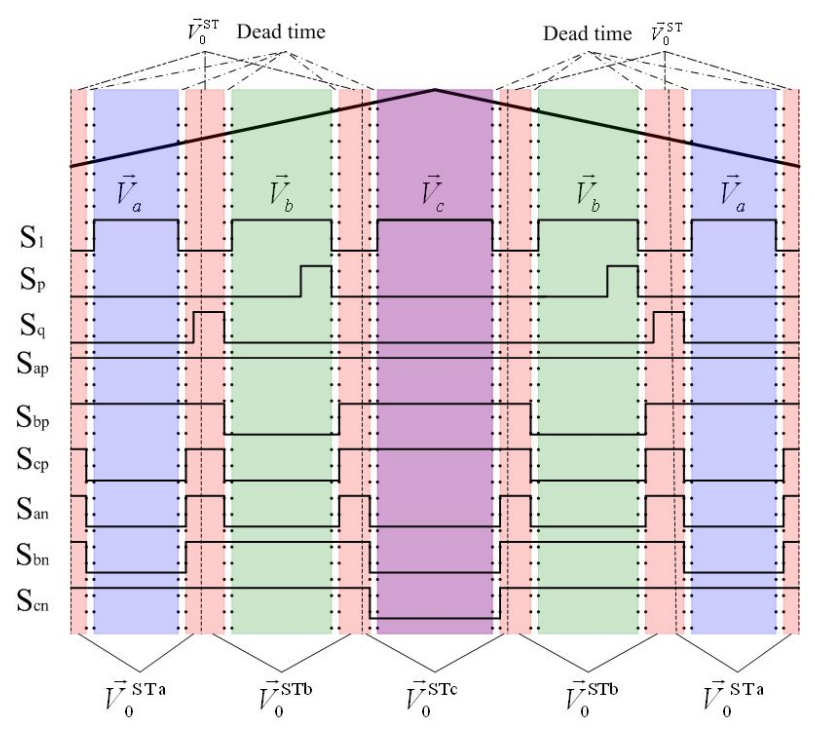

Fig. 11. Synchronous switching SVPWM.

of each stage can be analogously inferred and will not be discussed here.

\section{The Modulation of a BBI}

The line-to-line voltage space vectors of a BBI in the $\alpha-\beta$ coordinate system, listed in Table 1 , are transformed from the line-to-line voltages $v_{a b}, v_{b c}$ and $v_{c a} . \rho$ represents the vector modulus and $\theta$ is the corresponding rotating angle. Although 21 effectual shooting-through zero vectors exist in a buckboost inverter, the vector $V_{0}^{S T}\left(S_{a b c p}=S_{a b c n}=111\right)$ is only used in the modulation. The vectorial combination of the lineto-line voltage vector $\vec{v}$ from section I, illustrated in Fig. 10, is described by the following formula:

$$
\vec{v}=d_{1} \vec{V}_{1}+d_{2} \vec{V}_{2}+d_{3} \vec{V}_{0}+d_{4} \vec{V}_{0}^{\mathrm{ST}}
$$

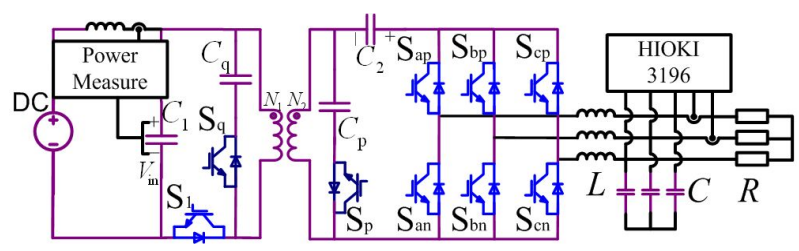

Fig. 12. Experimental schematic.

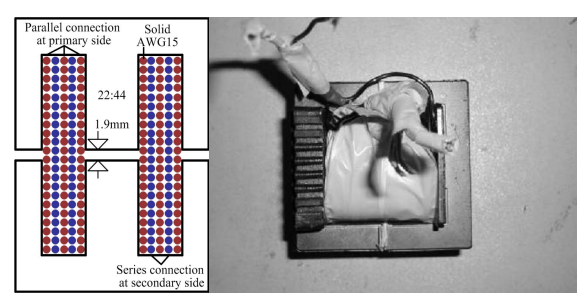

(a) Construction

(b) Prototype

Fig. 13. BBI transformer in Forward-Flyback mode.

where, $\vec{V}_{1}, \vec{V}_{2}$ and $\vec{V}_{0}$ are the inverting state vectors, and $\vec{V}_{0}^{\mathrm{ST}}$ is the vector of the shooting-through zero state.

The corresponding vector duty cycles are written as

$$
\begin{aligned}
d_{1} & =\sqrt{\frac{2}{3}} \frac{\rho \sin \left(\frac{\pi}{3}-\theta\right)}{v_{d c}} \\
d_{2} & =\sqrt{\frac{2}{3}} \frac{\rho \sin \theta}{v_{d c}} \\
d_{4} & =1-D
\end{aligned}
$$

where, $d_{1}+d_{2}+d_{3}+d_{4}=1$, and $\rho \leq \sqrt{3 / 2} D v_{d c}$.

At the steady state, the phase peak voltage of the inverter is expressed as

$$
v_{\text {phase }}^{\text {peak }}=\frac{M D}{2} v_{d c}=\frac{M G}{2} v_{C_{1}}
$$

where, $M$ is the modulation index, $M \in[0,2 / \sqrt{3}]$.

The buck boost factor of a BBI in buck-boost mode is expressed as:

$$
B B F=\frac{M G}{2}
$$

TABLE I

Line-To-Line Voltage SPACE Vectors

\begin{tabular}{|c|c|c|c|c|c|}
\hline$S_{1}$ & $S_{A}, S_{B}, S_{C}$ & $v_{a b}, v_{b c}, v_{c a}$ & Vector & $\rho$ & $\theta$ \\
\hline \multirow{5}{*}{1} & $10,01,01$ & $v_{d c}, 0,-v_{d c}$ & $V_{1}$ & & $30^{\circ}$ \\
& $10,10,01$ & $0, v_{d c},-v_{d c}$ & $V_{2}$ & & $90^{\circ}$ \\
& $01,10,01$ & $-v_{d c}, v_{d c}, 0$ & $V_{3}$ & $2^{0.5} v_{d c}$ & $150^{\circ}$ \\
& $01,10,10$ & $-v_{d c}, 0, v_{d c}$ & $V_{4}$ & $c$ & $210^{\circ}$ \\
& $01,01,10$ & $0,-v_{d c}, v_{d c}$ & $V_{5}$ & & $270^{\circ}$ \\
& $10,01,10$ & $v_{d c},-v_{d c}, 0$ & $V_{6}$ & & $330^{\circ}$ \\
& $10,10,10$ & $0,0,0$ & & & \\
& $01,01,01$ & $0,0,0$ & $V_{0}$ & 0 & $0^{\circ}$ \\
& $11,11,11$ & 0 & $V_{0}^{\mathrm{ST}}$ & 0 & \\
\hline
\end{tabular}

From (12), both the modulation index $M$ and the buck-boost voltage gains $G$ determine the buck-boost factor. When the fuel cell's output voltage drops with the load current, the BBI 


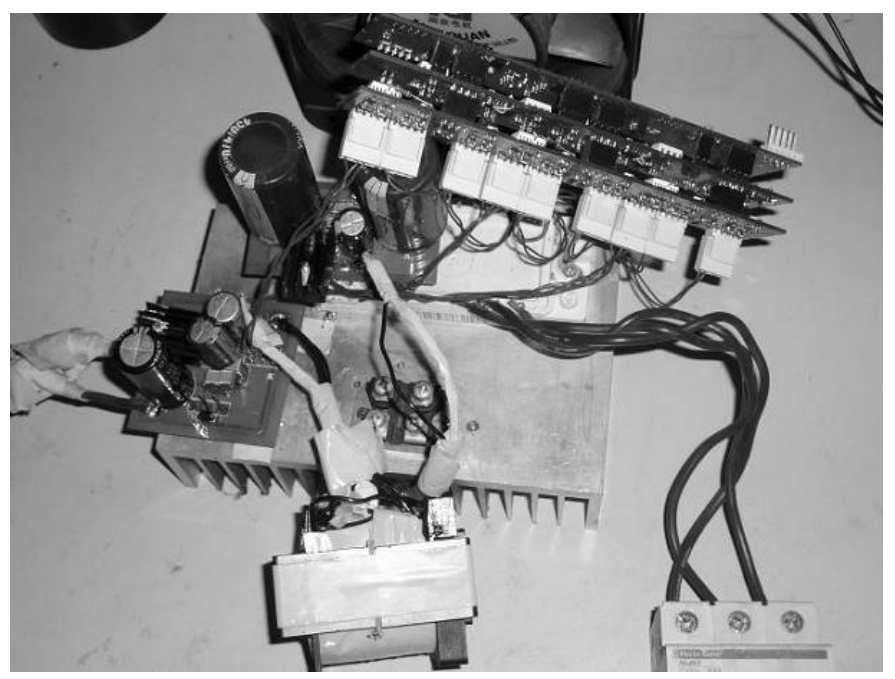

Fig. 14. BBI Prototype.

operating in buck-boost mode regulates the duty cycle of $S_{1}$ to control the dc link voltage of a conventional three-phase inverter, and the modulation index $\mathrm{M}$ is regulated to maintain the AC output.

Fig. 11 shows the switching sequence of synchronous switching SVPWM based on the triangular carrier method. This pulse width modulation is different from conventional SVPWM because the three-phase inverter's switches achieve ZVS and ZCS. During every switching period, there are five conventional vectors and six vectors of the shooting-through zero state in the symmetrical modulation. To avoid a short circuit between $S_{1}$ and the three-phase inverter, ten dead times should be inserted.

In this scheme, $V_{b}$ is half of the maximum vector among $\left|V_{1}\right|,\left|V_{2}\right|$ and $\left|V_{3}\right|$, while $V_{c}$ is the minimum vector. To reduce the inductance current ripple, the vectors of the shootingthrough zero state distribute between the neighboring vectors, which is expressed as:

$$
\frac{V_{0}^{S T a}}{2 V_{a}}=\frac{V_{0}^{S T b}}{2 V_{b}}=\frac{V_{0}^{S T c}}{2 V_{c}} .
$$

To reduce the switching frequency, $S_{p}$ can be merely turned on while the inverter operates at the $V_{b}$ vector, and $S_{q}$ can be turned on during the shooting-through zero state between the $V_{a}$ and $V_{b}$ vectors.

\section{Mathematical AnAlysis of BBI CirCuit}

When $S_{1}$ is turned off, the magnetizing current $i_{L m}$ charges the capacitor $C_{2}$ as shown in Fig. 8. The voltage ripple $\Delta V_{C 2} \leq 0.01 V_{C 2}$, is given by:

$$
\Delta V_{C 2} \leq \frac{\sqrt{3}}{4} \frac{D P_{i n}}{V_{C 2} f_{C} C_{2}}
$$

where, $P_{i n}$ is the input power, D is the $S_{1}$ duty cycle, $V_{C 2}$ is the average voltage of $C_{2}$ and $f_{C}$ is the triangle carrier frequency.

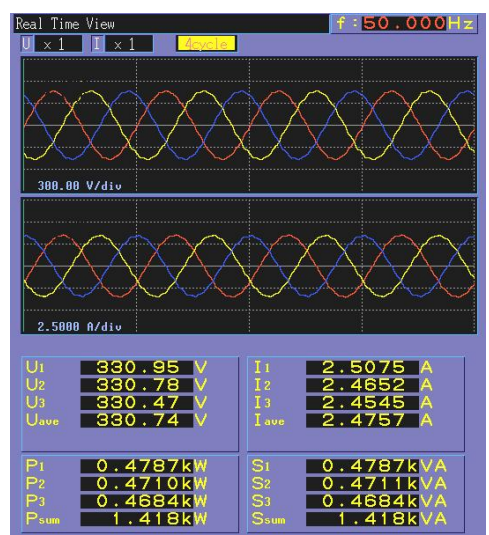

(a) load waveforms

(voltage: $300 \mathrm{~V} / \mathrm{div}$, current: $2.5 \mathrm{~A} / \mathrm{div}$ )

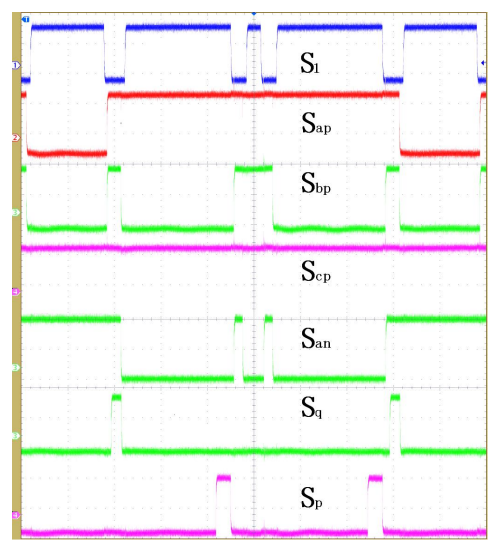

(b) IGBT drivers

(Voltage: $10 \mathrm{~V} / \mathrm{div}$, time: $20 \mu \mathrm{s} / \mathrm{div}$ )

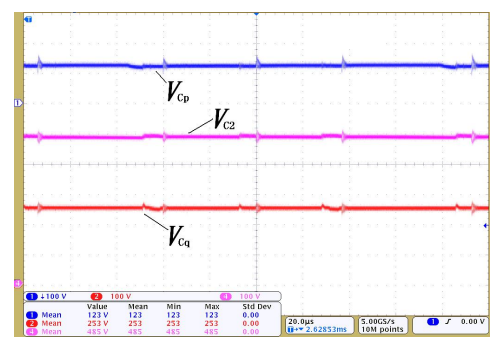

(c) Capacitors voltage

(Voltage: $100 \mathrm{~V} / \mathrm{div}$; time: $20 \mu \mathrm{s} / \mathrm{div}$ )

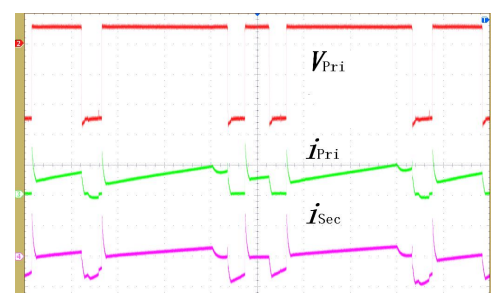

(d) Transformer waveforms

(Primary voltage $V_{\text {Pri }}, 100 \mathrm{~V} /$ div; primary current $i_{\text {Pri }}, 50 \mathrm{~A} / \mathrm{div}$; secondary current $i_{\mathrm{Sec}}, 20 \mathrm{~A} / \mathrm{div}$; time: $\left.20 \mu \mathrm{s} / \mathrm{div}\right)$

Fig. 15. Experimental results.

During the $C_{q}$ charging time $\tau_{\text {rise }}\left(t_{5}-t_{7}\right)$, the increased voltage $\Delta V_{C_{q 2}}$ is calculated by

$$
\Delta V_{C_{q 2}}=\sqrt{\Delta V_{C_{q 1}}^{2}+\frac{L_{L_{\sigma}} i_{L_{\sigma}}^{2}}{C_{q}}} .
$$


The rising time $\tau_{\text {rise }}$ of the $\Delta V_{C_{q 2}}$ is given by

$$
\tau_{\text {rise }}=\sqrt{L_{\sigma} C_{q}} \arctan \left(\sqrt{\frac{L_{\sigma}}{C_{q}}} \frac{i_{L_{\sigma}}}{\Delta V_{C_{q 1}}}\right) .
$$

During the $C_{q}$ discharging time $\tau_{S q}(t 8-t 9)$, the decreased voltage $\Delta V_{C_{q 3}}$ can be expressed by

$$
\Delta V_{C_{q 3}}=\Delta V_{C_{q 2}} \cos \left(\frac{\tau_{S_{q}}}{\sqrt{L_{L_{\sigma}} C_{q}}}\right) .
$$

In addition, the reversed maximum current $i_{L_{\sigma}}^{\text {rev }}$ can be calculated by

$$
i_{L_{\sigma}}^{\mathrm{rev}}=\sqrt{\frac{C_{q}}{L_{\sigma}}} \Delta V_{C_{q 2}} \sin \left(\frac{\tau_{S_{q}}}{\sqrt{L_{L_{\sigma}} C_{q}}}\right) .
$$

In order to minimize the increased voltage $\Delta V_{C_{q}}$, the $\Delta V_{C_{q 3}}$ must be zero. Therefore the switching-on time $\tau_{S_{q}}$ must be satisfied by:

$$
\tau_{S_{q}}=\frac{\pi}{2} \sqrt{L_{L_{\sigma}} C_{q}}
$$

Combining (18) and (19), the reversed current is derived from:

$$
i_{L_{\sigma}}^{\mathrm{rev}}=\sqrt{\frac{C_{q}}{L_{\sigma}}} \Delta V_{C_{q 2}} .
$$

The operation analysis of the clamping capacitor $C_{p}$ is the same as that of the clamping capacitor $C_{q}$.

According to equations (15) and (20) and the modulation, three consecutive charges for $C_{p}$ and $C_{q}$ are implemented before they are discharged, and therefore the clamping capacitors can be calculated by:

$$
\begin{aligned}
C_{p, q} & \geq 3 \frac{L_{\sigma} I_{\max }^{2}}{\Delta V_{C_{p, q}}^{2}} \\
I_{\max } & =I_{L_{m}}+K I_{\text {Phase }}
\end{aligned}
$$

where, $I_{L m}$ is the maximum value of the magnetizing current and $I_{\text {Phase }}$ is the peak value of the output current.

\section{EXPERIMENTAL RESULTS}

A $1.5 \mathrm{~kW}$ BBI prototype has been built to validate the proposed inverter, and the experimental schematic is shown in Fig 12. The main specifications and components are listed in Table 2, and the components' parameters are calculated according to (15)-(22). A DC source is used to simulate the fuel cell output characteristics, and the output voltage is regulated from $60 \mathrm{~V}$ to $110 \mathrm{~V}$.

Fig. 13 (a) shows the construction of a transformer in forward and fly-back mode, where there are five layers of the same winding with 22 turns AWG15 solid copper wires to form the sandwich. The 3 parallel primary windings overlap with the 2 series-wound secondary windings to reduce the leakage inductance. The transformer prototype and the BBI prototype are shown in Fig. 13 (b) and Fig. 14 respectively.

\begin{tabular}{|c|c|c|c|}
\hline$S_{1}$ & $\begin{array}{l}2 \mathrm{X} \text { IGBT } \\
\text { IKW75N60T } \\
600 \mathrm{~V} / 75 \mathrm{~A}\end{array}$ & $C_{p}$ & $11.5 \mu F / 450 \mathrm{~V}$ \\
\hline$S_{q}$ & $\begin{array}{c}\text { IGBT } \\
\text { IKW75N60T }\end{array}$ & $C_{q}$ & $21 \mu \mathrm{F} / 450 \mathrm{~V}$ \\
\hline Inverter & $\begin{array}{c}\text { FP25R12KE3 } \\
1200 V / 25 \mathrm{~A}\end{array}$ & $C_{2}$ & $235 \mu \mathrm{F} / 900 \mathrm{~V}$ \\
\hline$S_{p}$ & $\begin{array}{l}\text { GT15Q301 } \\
1200 \mathrm{~V} / 15 \mathrm{~A}\end{array}$ & $\Delta V_{C p}$ & $\leq 16.5 \mathrm{~V}$ \\
\hline$C_{1}$ & $470 \mu \mathrm{F} / 200 \mathrm{~V}$ & $\Delta V_{C q}$ & $\leq 12 \mathrm{~V}$ \\
\hline$L$ & $\begin{array}{l}1 \mathrm{mH} \text { ferrite } \\
40 \mu \mathrm{F} / 450 \mathrm{VAC} \\
\text { CBB65B }\end{array}$ & $\Delta V_{C 2}$ & $\begin{array}{l}\leq 1 \mathrm{~V} \\
530 \mathrm{~V}\end{array}$ \\
\hline$\tau_{S q}$ & $4.4 \mu \mathrm{s}$ & $\tau_{S p}$ & $6.7 \mu \mathrm{s}$ \\
\hline$f_{\text {Carrier }}$ & $5 \mathrm{kHz}$ & $f_{S 1}$ & $25 \mathrm{kHz}$ \\
\hline Transformer & \multicolumn{3}{|c|}{$\begin{array}{c}\text { EE65 ferrite core, } N_{1}: N_{2}=22: 44, \\
\text { total air gap } 3.8 \mathrm{~mm}, L_{m}=127 \mu \mathrm{H}, I_{L m}=55 \mathrm{~A} \\
L_{\sigma}=0.4 \mu \mathrm{H} \quad \text { (Primary side) }\end{array}$} \\
\hline
\end{tabular}

Fig. 15 shows the experimental results, where the input voltage is $60 \mathrm{~V}$, the load resistor is $80 \Omega, \mathrm{M}$ is 1.12 and $\mathrm{D}$ is 0.8 . The load waveforms measured by a power quality analyzer HIOKI 3196 are shown in Fig. 15 (a). Fig. 15 (a) shows
TABLE II

1.5KW BBI PROTOTYPE SPECIFICATIONS

the synchronous switching SVPWM in one switching cycle generated by the FPGA. Fig. 15 (c) shows that the $C_{2}$ voltage is boosted to $485 \mathrm{~V}$, while the output line-to-line voltage is $330.7 \mathrm{~V}$. The voltages of the clamping capacitors $C_{p}$ and $C_{q}$ are $123 \mathrm{~V}$ and $253 \mathrm{~V}$ respectively. These values are consistent with the theoretical values. The transformer waveforms during one switching period as shown in Fig. 15 (d) indicate that the transformer operates at the forward and fly-back mode.

The measured waveforms of the switch $S_{1}$ are shown in Fig. 16 (a), and the spike voltage of $S_{1}$ is clamped by $S_{p}$. Zero voltage turn-on of $S_{1}$ is shown in Fig. 16 (b) and the charge of $C_{s 1}$ during $S_{1}$ turn-off is shown in Fig. 16 (c). Fig. 16 (d)-(f) show the measured waveforms of the switch $S_{a n}$, and that the spike voltage of $S_{a n}$ is clamped by $S_{q}$. Zero voltage turn-on and Zero current turn-off are shown in Fig. 16 (e) and (f) respectively. Fig. 16 (g) and (h) show the measured waveforms of the clamping switches $S_{p}$ and $S_{q}$. Before $S_{p}$ and $S_{q}$ are turned on, the voltage of these switches have dropped to zero. Therefore, ZVS is achieved by gating on $S_{p}$ and $S_{q}$. While the resonant current of the clamping circuit is reversed through the anti-parallel diode of the clamping switches, the ZCS is also achieved by gating off $S_{p}$ and $S_{q}$.

The efficiency of the BBI system has been experimentally evaluated, and the system losses include the losses from the output filters ( $\mathrm{L}$ and $\mathrm{C}$ ) and the auxiliary circuits. The auxiliary circuits consist of transducers, gate drivers and a digital control board, and the total power consumed by auxiliary circuit is less than $10 \mathrm{~W}$. While the input voltage increases from $60 \mathrm{~V}$ to $110 \mathrm{~V}$ and the voltage gain is 5 , the efficiency of the BBI increases from $85.84 \%$ to $87.54 \%$, and output power increases from $550 \mathrm{~W}$ to $1767 \mathrm{~W}$, as shown in Fig. 17 (a). When the voltage gain increases from 4 to 8 with $60 \mathrm{~V}$ of input voltage, the efficiency changes from $84.5 \%$ to $86.2 \%$, as shown in Fig. 17 (b). Therefore, the BBI performs with improved efficiency with a wide range of input voltages. Although the efficiency 


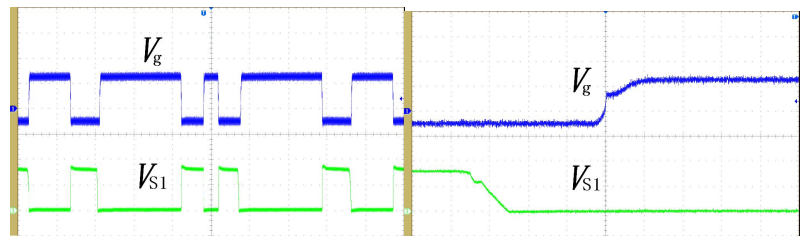

(a) $S_{1}$ clamping voltage

(b) $S_{1}$ zero voltage turn-on

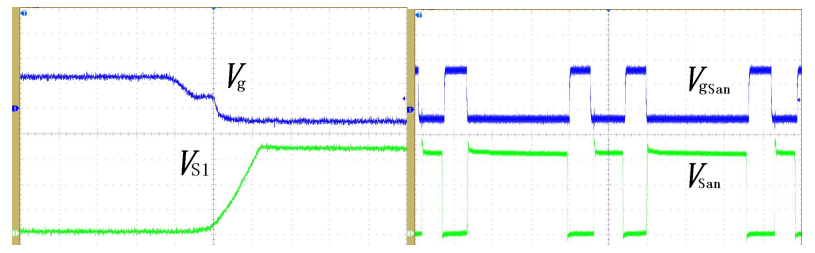

(c) $C_{S 1}$ charge during turn-off

(d) $S_{a n}$ clamping voltage

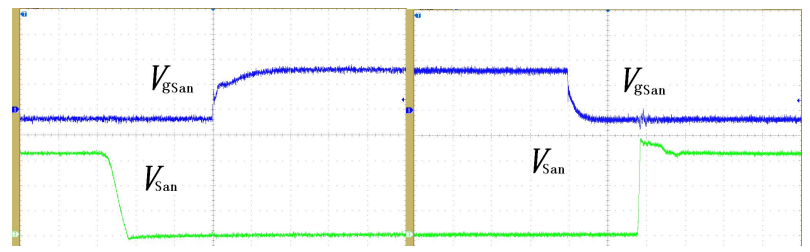

(e) $S_{a n}$ Zero voltage turn-on

(f) $S_{a n}$ Zero current turn-off

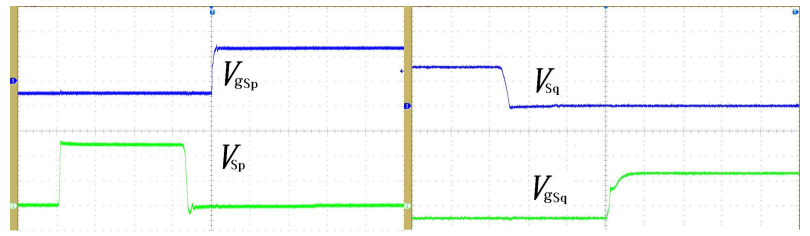

$\begin{array}{ll}\text { (g) Zero-voltage turn-on of } S_{p} & \text { (h) Zero-voltage turn-on of } S_{q}\end{array}$

Fig. 16. Soft-switching waveforms of the switches.

$V_{S 1}, V_{S a n}, V_{s p}, V_{s q}(100 \mathrm{~V} / \mathrm{div}), V_{g}(10 \mathrm{~V} / \mathrm{div})$

of the prototype is not very high due to an unimproved transformer, it is worth expecting that the BBI's efficiency can be improved up to $92 \%$ by using an optimized transformer and circuit layout.

\section{CONCLUSIONS}

A new isolated soft-switching bidirectional buck-boost inverter has been proposed for fuel cell applications. The operation, analysis, features and design considerations have been presented. The experimental results for a $1.5 \mathrm{~kW}, 25 \mathrm{kHz}$ prototype verify the operation principle.

The main switches achieve ZVS and ZCS by using a novel synchronous switching SVPWM. The active clamping circuits reduce the spike voltages of the switches. The experimental results indicate that the inverter maintains efficient conversion with a wide range of input voltages and voltage gains. Therefore, the BBI is suitable for power applications that require a wide range of input voltages and voltage gains.

\section{ACKNOWLEDGMENT}

This work was supported by a key project for the National Supporting Technology: Power Electronic Devices and Power Integration (2007BAA12B01).

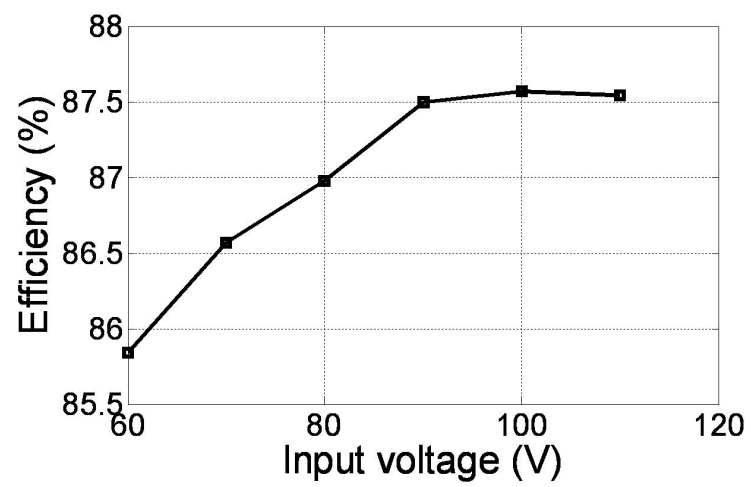

(a) Various input voltage

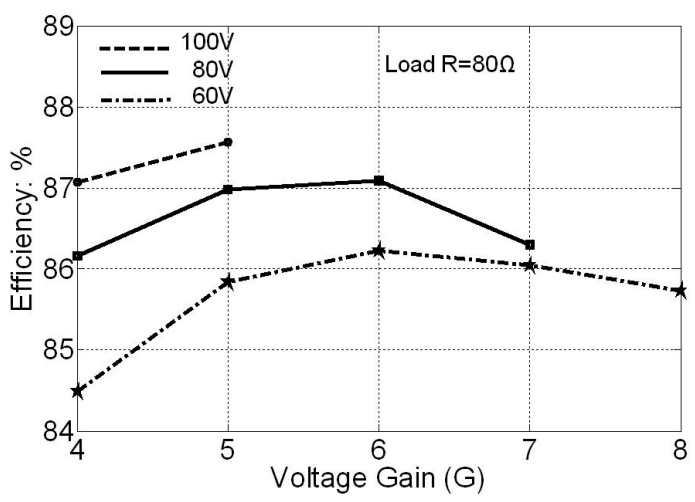

(b) various voltage gain $G$

Fig. 17. Efficiency of BBI.

\section{REFERENCES}

[1] DOE Fuel Cell Handbook, $7^{\text {th }}$ ed., EG\&G Technical Services Inc., Morgantown, WV, pp: 8.27-8.44, 2004.

[2] X. Yu, M. R. Starke, L. M. Tolbert, and B. Ozpineci, "Fuel cell power conditioning for electric power applications: a summary," IETElectr. Power Appl., Vol.1, No. 5, pp. 643-656, Sep. 2007.

[3] S. K. Mazumder, R. K. Burra, and K. Acharya, "A ripple-mitigating and energy-efficient fuel cell power-conditioning system," IEEE Trans. Power Electron., Vol. 22, No. 4, pp.1437-1452, Jul. 2007.

[4] P. T. Krein, R. S. Balog, and G. Xin, "High-frequency link inverter for fuel cells based on multiple-carrier PWM," IEEE Trans. Power Electron., Vol. 19, No. 5, pp. 1279-1288, Sep. 2004.

[5] M. Marchesoni, C. Vacca, "New DC-DC converter for energy storage system interfacing in fuel cell hybrid electric vehicles," IEEE Trans. Power Electron., Vol. 22, No. 1, pp. 301-308, Jan. 2007.

[6] R. J. Wai, R. Y. Duan, J. D. Lee, and L. W. Liu, "High-efficiency fuelcell power inverter with soft-switching resonant technique," IEEE Trans. Energy Convers., Vol. 20, No. 2, pp. 485-492, Jun. 2005.

[7] G. K. Andersen, C. Klumpner, S. B. Kjær, F. Blaabjerg, "A new power converter for fuel cells with high system efficiency," International Journal of Electronics, Vol. 90, No. 11, pp. 737-750, Nov. 2003.

[8] R. Gopinath, S.S. Kim, J. H. Hahn, P. N. Enjeti, M. B. Yeary, and J. W. Howze, "Development of a low cost fuel cell inverter system with DSP control," IEEE Trans. Power Electron., Vol. 19, No. 5, pp. 1256-1262, Sep. 2004.

[9] S. Jang, C. Won, B. Lee, and J. Hur, "Fuel cell generation system with a new active clamping current-fed half-bridge converter," IEEE Trans. Energy Convers., Vol. 22, No. 2, pp. 332-340, Jun. 2007.

[10] X. Kong, A. M. Khambadkone, "Analysis and implementation of a high efficiency, interleaved current-fed full bridge converter for fuel cell system," IEEE Trans. Power Electron., Vol. 22, No. 2, pp. 543-550, Mar. 2007.

[11] S. Jung, Y. Bae, S. Choi, and H. Kim, "A low cost utility interactive inverter for residential fuel cell generation," IEEE Trans. Power Electron., Vol. 22, No. 6, pp. 2293-2298, Nov. 2007. 
[12] J. Wang, F. Z. Peng, J. Anderson, A. Joseph, and R. Buffenbarger, "Low cost fuel cell converter system for residential power generation," IEEE Trans. Power Electron., Vol. 19, No. 5, pp. 1315-1322, Sep. 2004.

[13] J. L. Duarte, M. Hendrix, and M. G. Simões, "Three-port bidirectional converter for hybrid fuel cell systems," IEEE Trans. Power Electron., Vol. 22, No. 2, pp. 480-487, Mar. 2007.

[14] J. Lee, J. Jo, S. Choi, and S. B. Han, "A 10-kW SOFC low-voltage battery hybrid power conditioning system for residential use," IEEE Trans. Energy Convers., Vol. 21, No. 2, pp. 575-585, Jun. 2006.

[15] J. S. Lai, S. Y. Park, S. Moon, and C. L. Chen, "A high-efficiency 5$\mathrm{kW}$ soft-switched power conditioning system for low-voltage solid oxide fuel cells," in Proc. PCC '07 Conf., Nagoya Japan, pp. 463-470, 2007.

[16] H. M. Tao, J.L. Duarte, M.A.M. Hendrix, "Line-interactive UPS using a fuel cell as the primary source," IEEE Trans. Ind. Electron., Vol. 55, No. 8, pp. 3012-3021, Aug. 2008.

[17] M.H. Todorovic, L. Palma, P.N. Enjeti, "Design of a wide input range DC-DC converter with a robust power control scheme suitable for fuel cell power conversion," IEEE Trans. Ind. Electron., Vol. 55, No. 3, pp. 1247-1255, Mar. 2008.

[18] J. M. Kwon, B. H. Kwon, "High step-up active clamp converter with input-current doubler and output-voltage doubler for fuel cell power," IEEE Trans. Power Electron., Vol. 24, No. 1, pp. 108-115, Jan. 2009.

[19] K.Jin, X.B. Ruan, "Hybrid full-bridge three-level LLC resonant converter - a novel DC-DC converter suitable for fuel-cell power system," IEEE Trans. Ind. Electron., Vol. 53, No. 5, pp. 1492-1503, May 2008.

[20] J. Kikuchi and T. A.Lipo., "Three-phase PWM boost-buck rectifiers with power-regenerating capability," IEEE Trans. Ind. Appl., Vol. 38, No. 5, pp. 1361-1369, Sep. 2002.

[21] C. T. Pan and J. J. Shieh, "A single-stage three-phase boost-buck AC/DC converter based on generlized zero-space vectors," IEEE Trans. Power Electron., Vol. 14, No. 5, pp. 949-958, Sep. 1999.

[22] P.C.Loh., P.C.Tan., F.Blaabjerg., and T.K.Lee., "Topological development and operational analysis of buck-boost current source inverters for energy conversion applications," in Proc. IEEE PESC'06 Conf., Soul Corea, pp. 1-6, 2006.

[23] C. Klumpner, "A new single-stage current source inverter for photovoltaic and fuel cell applications using reverse blocking IGBTs," in Proc. IEEE PESC'07 Conf. Orlando USA, pp. 1683-1689, 2007.

[24] F. Z. Peng, M. Shen, K. Holland, "Application of Z-source inverter for traction drive of fuel cell - battery hybrid electric vehicles," IEEE Trans. Power Electron., Vol. 22, No. 3, pp. 1054-1061, May 2007.

[25] D. L. Chen. and L. Li, "Novel static inverters with high frequency pulse DC link," IEEE Trans. Power Electron., Vol. 19, No. 4, pp. 971-978, Jul. 2004.

[26] K. Fukushima, T. Ninomiya, S. Abe, I. Norigoe, Y. Harada, K. Tsukakoshi, and Z. Dai, "Steady-state characteristics of a novel DCAC converter for fuel cells," in Proc. IEEE INTELEC'07 Conf., pp. 904-908, 2007.

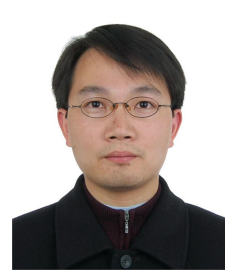

Lianghua Zhang was born in Hubei Province, China in 1980. He received his B.S. and M.S. in Electrical Engineering from Xi'an Jiaotong University, China, in 2002 and 2005, respectively. Since 2005, he has been with the Department of Electrical Engineering, Xi'an Jiaotong University, where he is currently pursuing his Ph.D. in Engineering Science. His research interests are in the areas of power electronics integration, new circuit topologies, motion control systems, uninterruptible power supplies and dc-dc power supplies.

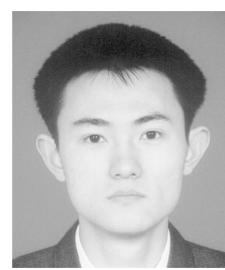

Xu Yang was born in China in 1972. He received his B.S. and Ph.D. in Electrical Engineering from Xi' an Jiaotong University, Xi'an, China, in 1994 and 1999 respectively. He has been a member of the faculty of the School of Electrical Engineering, Xi'an Jiaotong University since 1999 , where he is presently a Professor. From November 2004 to November 2005, he was with the Center of Power Electronics Systems (CPES), Virginia Polytechnic Institute and State University, Blacksburg, VA, as a Visiting Scholar. He then came back to Xi'an Jiaotong University, and began teaching and doing research in the areas of power electronics and industrial automation. His current research interests include soft switching topologies, PWM control techniques, power electronic integration, and packaging technologies.

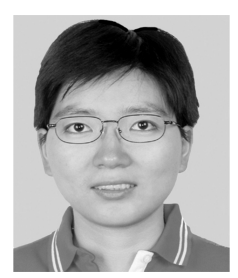

Wenjie Chen was born in Xi'an, China, in 1974. She received her B.S., M.S. and Ph.D. in Electrical Engineering from Xi'an Jiaotong University, Xi'an, China, in 1996, 2002 and 2006, respectively. She has been a member of the faculty of the School of Electrical Engineering, Xi'an Jiaotong University since 2002, where she is currently an Associate Professor. Her main research interests include soft-switching dc/dc converters and active filters, and power electronic integration.

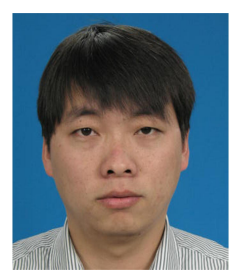

Xiaofeng Yao was born in Shaanxi, China, in 1985 He received his B.S. in Electronic Engineering from Xi' an Jiaotong University, China, in 2007, where he is currently pursuing his M.S. in the Power Electronics \& Renewable Energy Research Center (PEREC). His main research interests include DC/DC converters and singlephase grid-connected inverters based on photovoltaic modules. 